\title{
KAROL BERMÚDEZ*
}

\section{PARA ENTENDER A LYOTARD EN EL AM BITO DE LA POSMODERNIDAD}

\section{Presentación}

\section{A Rosa}

La intención de este escrito se origina en la dificultad con que tropieza el lector desprevenido, quien atraído por la seducción didáctica e inocente del título de un libro, en este caso Lo posmodernidad explicada a los niños de J. F. Lyotard, pronto descubre que ni el rótulo, ni el listado prudente de la contra-carátula, ni la advertencia confidente de los editores en su prefacio, facilitan lo que se va a constituir en un transitar difícil y un entender penoso.

Des de el primer párrafo nos encontramos con un escrito denso y complejo, por la abundancia de referencias a un ámbito exótico y de cuya constitución y características este trabajo pretende ofrecer alguna orientación.

Para cumplir con este propósito de ilustración hetero y autodidacta e identificar el contexto donde Lyotard es figura destacada, consideramos pertinente seguir el hilo y la madurez expositiva de la obra de Wolfgang Welsch, Unsere postmodeme Moderne, Nuestros Modernos Posrnodernos, que en idioma alemán ya se halla en su cuarta edición y cuya traducción al español aportaría un inmenso beneficio a todos aquellos interesados por un tema que no sólo está de moda (si es que en filosofía se debe y se puede hablar de moda), sino que parece de la más alta pertinencia filosófica para participar en el debate filosófico actual ${ }^{1}$

\section{Introducción}

La verdadera posmodemidad no es un fenómeno limitado, ni se refiere sólo a las condiciones norteamericanas o al pensamiento francés. Decimos verdadera porque parece persistir una terca confusión en lo que a este concepto se refiere. Se ha creído, por ejemplo, que en un cruce perverso y polimorfo de líbido con economía, cibernética y cinismo, esoterismo olvidado y simulación, agregándole algo de New Age y Apocalipsis, se obtendrá el coctel perfecto que podrá ser disfrutado como posmodernidad. Se ha creído también que es el engendro de diferentes mezclas científico-universales, donde entrarían Lacan, Derridá y cualquier otro escenario en que se acomode una cultura del "chic" y de la moda. Para la prueba un botón: un autor Ilamado Klaus Laermann ha descrito en un

\footnotetext{
${ }_{1}^{*}$ Profesor. Departamento de Bellas Artes. Universidad Pedagógica Nacional.

${ }^{1}$ Cf. Wolfgang Welsch. Unsere postmoderne Moderne. Akademie Verlag. Vierte Auflage. Berlin 1993.
} 
artículo estas manifestaciones de una manera brillante como su propio título: Lacan-can y Derridadá. Sobre la francolatría en las ciencias de la cultura ${ }^{2}$

La posmodemidad no es tampoco, nos dice Welsch, una invención de teónicos del arte, artistas y filósofos, sino más bien que nuestra realidad y nuestro Lebenswelt devinieron posmodernos. En esta era de las telecomunicaciones y del denso tráfico aéreo, lo heterogéneo se ha hecho tan cercano y cotidiano, que todo se empotra de tal manera que la simultaneidad de lo no-simultáneo se nos convirtió en segunda naturaleza. La posmodernidad no se inventó esta situación sino que la refleja. No elude la mirada que esta situación cautiva, sino trata de hacer frente a las exigencias del tiempo y su pluralismo quiere responder a estas exigencias tanto en el fondo como en su problemática.

Veamos a grandes rasgos cuáles son sus características principales:

a) Va a la sustancia de esta situación, porque encara sus raíces. Por ello se habla de "pluralismo radical".

b) Es esa fase histórica en que la pluralidad se reconoce como constitutivo fundamental de las sociedades y por ello el modelo plural de sentido y acción se hace urgente, inclus o dominante y obligante.

c) Representa una intrínseca visión positiva, que traduce en lo social una inseparable vocación por la democracia real.

d) Se manifiesta en formas concretas de la razón que se remiten unas a otras autónomamente, como plenas de sentido: hay formas diversas del saber, hay proyectos de vida, hay modelos de acción.

e) Y ya que desde Platón la filos ofía occidental tiene una vocación fototrópica, la posmodernidad se experimenta a sí misma con luz propia: la luz del contenido de los diferentes saberes. Ya no cuenta el viejo modelo de un sol para todo y sobre todo. Este sol único es personaje impertinente. Conclusión:

Verdad, Justicia y Humanidad se conjugan en plural. Esto tiene, como consecuencia prohibitiva y reverso de este pluralismo de principios, su opción política antitotalitaria.

f) La posmodemidad no es relativismo banal. Su ímpetu filosófico es moral; su opción va a la pluralidad de formas de vida y formas de comportamiento, de tipos de pensamiento y concepciones sociales, de sistemas de orientación y defensa de minorías. No afima acríticamente ningún statu quo.

${ }^{2}$ Laemann. K. "Lacancan und Derridadá. Über die Frankolatríe in den Kulturwissenschaften". Kursbuch 84. 1986, 34-43. 
g) La congruencia de los fenómenos posmodernos en arquitectura, literatura y artes, así como en el fenómeno social de lo económico y lo político, y por encima de estos en las teorías científicas, es más que evidente. Gracias a esta congruencia es lo "posmoderno" un concepto y no sólo un slogan, y puede desenvolverse como conceptualización de manera que no sea tomado sólo como un pensamiento de moda.

h) La posmodernidad no es, corno equivocadamente se toma, una trans o antimodernidad. Lleva en sí lo moderno pero se despide del modemismo. Deja atrás la ideología de la potenciación, de la innovación, de la revisión (Überholung) y la superación (Überwindung). Deja igualmente atrás la dinámica de los ismos y su aceleración.

i) La condición histórica de lo posmoderno no es compatible con las categorías de la Überholung y la Überwindung, como lo veremos más adelante, en relación con la historia antigua, ni tampoco con la reciente, a la que llamamos moderna.

j) La posmodernidad, insiste Welsch, está en esencia fundada éticamente, exigiendo un nuevo trato con la pluralidad, y precisa de una pluralidad que por causa de su radicalidad se hace más difícil. Pide por ello una ética novedosa, una ética cortada a la medida de esa pluralidad radical y conflictiva; claro está, para todos aquellos que hemos sido educados en la comodidad de las propuestas unificadoras.

k) Aparece entonces el problema de la razón; la pluralidad entra en escena entre otras- como formas plurales de racionalidad. Sus relaciones no son reducibles a una forma única de racionalidad ni puede ser regulada por una pretendida hiper-racionalidad. Una heterogeneidad de la racionalidad tampoco puede tener la última palabra; el dogma de una heterogeneidad absoluta no soporta la prueba de un examen minucioso.

¿Qué quieren entonces los posmodemos? Quieren desarrollar una concepción de la razón que no ignora la medida de las diferencias reales ni tampoco concede importancia excesiva a las exigencias comunicativas, sino que muestra los límites de las diversas formas de racionalidad $y$ defiende las transiciones $y$ confrontaciones entre ellas, posibilitándolas y completándolas. Renueva así la función clásica implícita de la razón frente a las formaciones del entendimiento. Este concepto es pecíficamente "posmodemo" de razón, Wels ch lo identifica en sucesivos y magistrales desarrollos como razón transversal.

Armados de este marco informativo y referencial, vamos a intentar exponer lo que ha sido la experiencia de nuestra lectura, no sin antes tomar la precaución de detenemos todavía sobre la genealogía del término posmodernidad. 


\section{Genealogía, espectro y sentido del concepto}

En 1870, John Watkins Chapman, un pintor inglés de salón, pretende precursar "una pintura posmodema"; posmodemo quiere decir aquí una pintura que se pretende más de avanzada que el impresionismo francés ${ }^{3}$. Sin embargo este término, según este tipo de investigación arqueológica, parece que quedó sin efectos posteriores. En un segundo momento, asoma la cabeza la expresión posmoderno en 1917, cuando Rudolf Pannwitz habla de"hombres posmodemos" en su libro La crisis de la cultura europea ${ }^{4}$. ¿Que dice en este libro? el hombre posmoderno deportivamente acerado por el nacionalismo, militaris ta consciente, educado y religioso, es un molusco incrustado, un compromiso entre decadente y bárbaro, sobreviviente del útero de la gran decadencia de la radical revolución del nihilismo europeo". Según Welsch, toda esta parrafada es una paráfrasis de Nietzs che, y confirmamos aquí que Nietzsche, como lo plantea Habermas en el Discurso filosófico de la Modernidad ${ }^{5}$, constituye el eje sobre el cual se articulan lo moderno y lo posmoderno.

No sobra aquí reseñar igualmente algunos cortes históricos que identifican la posmodernidad en Hispanoamérica y España, en el escenario de su producción poética:

a) Una etapa breve identificada como modemismo, que vade 1896 a 1905.

b) Un intermezzo corto y reactivo entre dos modernismos, que se rotula como posmodernismo, que va de 1905 a $1914^{6}$.

c) Ultramodemismo, de 1914a $1932^{7}$.

\section{Fecha clave : 1969}

La fecha decisiva para el propósito que nos ocupa, se sitúa en 1969. Diez años luego del comienzo del debate literario se estabiliza el témino: hay posmodernidad allí donde la pluralidad fundamental de lenguajes, modelos, formas de experiencia, se practican, pero no sólo en obras diferentes sino en una y la misma obra, es decir, de manera interferente. El término gana, pues, en este debate los contornos de un concepto verdadero y pasa de ser un vocablo negativo, el del adomecimiento y ensoñamiento de los fenómenos antes citados, (Pannwitz et al.),

\footnotetext{
${ }^{3}$ Cf. Dick Higgins, A Dialectjc of Centuries. Notes Towards a Theory the New Arts. New York, 1978, 7.

${ }^{4}$ Cf. Rudolf Pannwitz, Die Krisis dereuropäischen kultur. Werke. Bd. 2, Nümberg, 1917, 64.

${ }^{5}$ Cf. Jürgen Habermas, El discurso filosófico de la Modernidad. Taurus, Buenos Aires, 1989, 4. Entrada en la Posmodernidad; Nietzsche como plataforma giratoria. pp. 109-135.

${ }^{6}$ Véase también R. Gutiérrez Girardot Modernismo, supuestos históricos y culturales. FCE, 1987. Bogotá. Sobre todo la cronología al final de esta obra. Págs. 123-132.

${ }^{7}$ Cf. Federico de Onís, Antología de la Poesía Española e Hispanoamericana. Madrid, 1934. XVIII.
} 
a ser un vocablo positivo que señala redes de comunicación y que tiene decidida pluralidad como contenido.

Inscritos en este panorama, que a pesar de su amplitud no pretende ser exhaustivo por el carácter limitado de este escrito, intentaremos una relectura del texto citado para una mejor intelección del discurso de Lyotard, dejando en suspenso y para un momento ulterior, qué tan niños o tan adultos somos para merecer matrícula en el ámbito denso y polémico de la posmodernidad.

\section{Las voces de la crítica a la posmodernidad}

Welsch califica de síndrome recriminatorio habitual el conjunto de reproches de diverso calibre que se han granjeado los portabanderas de la posmodernidad, y muy en especial, quien parece ser su figura central, Jean François Lyotard. En el texto que leímos, ya nos advertían sus editores, que tuvieron que vencer la resistencia del autor, argumentando que querían contribuir a "lavarlo de ciertas acusaciones, entre otras, la de irracionalismo, neoconservatismo, liberalismo cándido, nihilismo y cinismo"; lo que no alcanzan a advertir los editores es que la diatriba abarca un espectro aún mayor. Se dice por ejemplo que la posmodemidad se propaga cual una peste:

a) Allí donde la creación vital no se guía por criterios seguros sino que sigue tendencias estéticas y el "chic" de la moda.

b) Allí donde el hedonismo del sujeto es la pauta del actuar.

c) Alí donde la vida del mundo industrializado se repliega hacia refugios estéticos y en una percepción disgregada, fragmentada, disuelve el continuum de la vida cotidiana.

d) La percepción se convertiría así, según estos mismos detractores, en el canon de la realidad y por ello caen las visiones posmodernas del mundo en las trampas del esteticismo.

e) Desde el punto de vista social e histórico, se propagaría la peste del posmodernismo allí donde la colcha de retazos de la memoria aparece y los grupús culos que tanto se multiplican se convierten en sectas, de tal manera que en general reina una excentricidad desbocada. Concluyen entonces que diversificación y fragmentación impregnan el diseño social de la posmodemidad y que como tal, ni siquiera merecería es te nombre, pues se trataría propiamente de un anarquismo promovido y es téticamente altisonante.

Ahora entendemos por qué en la advertencia de los editores, Lyotard denuncia un problema banal y recurrente en la lectura de los textos filosóficos, que nos brinda la primera pista para descifrar el código que nos hará posible entender el irónico enigma oculto en el título: ¿Quiénes son los niños a quienes Lyotard 
explica la Posmodernidad? Dice Lyotard que en vez de leer, lo que debe llamarse leer, y refutarlo ad rem, sus adversarios operan preferencial mente ad hominem y por categorías manidas y que no conviene a la deferencia que se le debe al pensar, el prestarse a polémicas de esta laya"8.

¿,Por qué se le acusa de irracionalismo’?

a) En cuanto al aspecto ético, porque niega las posibilidades de fundamentación última, disuelve la fundamentación de los deberes y se burla de los us os tradicionales de todo lo fundamentado.

b) En cuanto a lo político, porque se tildan de totalitarias las experiencias de la razón y la racionalidad, ya sea dialéctica o neorromántica, se considera represiva.

c) Porque se quiebra el logocentrismo y la frontera entre filosofía y poesía se borra. Tratan a la verdad, insisten estos alegres detractores, como aquella mujer vieja (opinión que tiene su origen en Melanchton y Nietzsche según nos lo recuerda el muy informado Welsch) que huele a Grecia y debe ser desterrada definitivamente.

\section{La posmodernidad explicada por Lyotard a sus críticos}

Pasemos ahora a la otra orilla y tratemos de ubicarnos en los lineamientos fundamentales del planteamiento del acusado ${ }^{9}$. Lyotard nos dice que en su más extrema simplificación, posmodernidad significa no otorgarle más credibilidad a los meta-relatos.

Fundamentalmente estos meta-relatos son tres, a saber:

a) El de las Luces, sobre la emancipación de la humanidad.

b) El Idealista, sobre la teleología del Espíritu.

c) El Historicista, sobre la hermenéutica del sentido.

Estos relatos ya no contienen su carga intrínseca de obligatoriedad ni tienen fuerza legitimatoria; a diferencia de los mitos, no buscan su legitimidad en un acto original fundador, sino en un futuro que debe advenir, es decir, que es una idea por realizar, y esta idea, ya sea de libertad, de luces, de socialismo, etc., tiene un valor que se legitima en su pretensión universalizante y pretende orientar todas las real ida-des humanas, lo cual impregna entonces a la modemidad de su modo

\footnotetext{
${ }^{8}$ Jean François Lyotard. Le postmoderne expliqué aux enfants. Le livre de poche. Editions Galilée. Paris 1968. p. 5.

${ }^{9}$ Para lo que sigile. Cl. J. F. Lyotard, La condition posmoderne. Rapport sur le savoir. Paris. 1979. Existe traducción al español.
} 
característico: el Proyecto, ese proyecto que según Habemas, debe ser renovado, restituido y retomado, porque quedó inacabado.

El argumento de Lyotard es que ese proyecto no ha sido abandonado ni olvidado, sino destruido y más exactamente, "liquidado". El símbolo y paradigma de esta liquidación es Auschwitz, que significa además la no-realización o inacabamiento trágico de la modemidad.

En el vacío que parece haber dejado Auschwitz, en las cabezas pensantes de la posmodernidad, no se ve ningún meta-relato á la vista, que sea realmente o parezca universal. Esto constituye precisamente lo que Lyotard Ilama la "condition posmoderne", lo cual puede Ser reconocido aún por los más ardientes partidarios del atractivo paradigma de los marcosabarcalo-todo. Es posible que entre estos partidarios se encuentren todos los alegres secuaces devotos de la ética discursiva y sus ensoñaciones trascendentales, siguiendo la expresión de Hans Albert $^{10}$

No tenemos además insight, ni suficiente ni confiable, sobre la posibilidad de tales meta-relatos mega-integradores. La historia reciente ha agrietado la credibilidad del meta-relato ya que hemos entrevisto la trampa de la Totalidad, pero en compensación, dicen los posmodemos, hemos aprendido a conocer, reconocer y observar su pluralidad genérica tal como se revela en los proyectos totalizantes, que entre más se esfuerzan en cumplir su acometido, más claras aparecen sus particularidades. La Verdad, la Legitimación, la Humanidad se hallan para nosotros aquende de la concentración convulsiva de los metarelatos. Según Antonio Villani, "la pérdida del centro se convierte en el nuevo mito de la conciencia contemporánea"11

\section{Rememorando a Hegel}

Lyotard se pregunta a qué especie de unidad se refiere Habermas, cuando la meta que visualiza el proyecto modemo es la constitución de una unidad sociocultural en el seno de la cual todos los elementos de la vida cotidiana y del pensamiento encontrarían su unidad como en un todo orgánico ${ }^{12}$. Esta explícita alusión a Hegel nos obliga a recordar que para éste, sólo el Todo podía ser lo verdadero, y realizaba su credo a través de una concepción de unidad que no excluía lo diferente sino que lo incluía en la medida en que la unidad como tal la pensaba como unidad y diferencia.

Es conveniente recordar que el pensamiento unificante de Hegel era uno de los ejes de esta modernidad que rechazan los posmodemos, por lo cual nos parece

\footnotetext{
${ }^{10}$ Albert Hans, Traktat über Kritische Vernunft. (Tratado sobre la razón crítica). Tübingen 1980. (No tenemos noticia sobre traducción española de esta obra).

${ }^{11}$ Antonio Villani. Le chiavi del postmoderno: un dialogo a distanza. il Mulino. 1986.

${ }^{12}$ La posmodernidad (explicada a los niños). P. 13. 
pertinente hacer aquí la breve síntesis de las tres fases del trabajo del espíritu hegeliano:

a) El trabajo de ese espíritu que sale de sí nr es fácil: necesita un esfuerzo desmedido ya que la diferencia es de antemano una carrera de obstáculos que sirve al espíritu como proeza y prueba. (La metáfora es de Welsch y su belleza y pertinencia nos obligan a su trans cripción casi literal).

b) Es un acto de fuerza y una empresa de superación.

c) El regreso del despliegue del espíritu, el reencontrarse y el autoapropiarse desde el desgarramiento, constituye su meta y su mandato. Veremos más adelante, en el epílogo de es te trabajo, que el concepto de deconcertation face au texte es de fuerte

raigambre hegeliana. $^{13}$

La resistencia que en este proceso ejercen las diferencias es, según la interpretación de Welsch, el médium del auto despliegue del espíritu. Las diferencias surgen del hecho que "el Uno y lo mismo se configura a sí mismo diferente"; diferencia es producto diferenciado y medio escalar de lo Uno. La Unidad vale sin cuestionamiento. La diferencia es sólo su elíxir y su garante provocador. Para Hegel todo esto significa que la apariencia de diferenciación máxima cobija una realidad de diferenciación mínima.

Nos ha parecido necesario este breve interludio hegeliano para contrastar el clima de esta filosofía, que se funda en unidad totalizadora con el planteamiento de Lyotard, cuando califica la filosofía posthegeliana como una filosofía de despedida de la totalidad, una filosofía del desmonte de las agarraderas de la unidad; una filosofía que consume el proceso que Lyotard descubre como despedida de la modemidad y tránsito a la posmodernidad.

La supuesta historia universal única se quebró en la pluralidad de diferentes mundos históricos, lo que se repite en el siglo XX, en la concepción heideggeriana de la Seingeschichte, Historia del ser, o en la presentación foucaultiana del saber histórico. Tanto la "Schickung", Destinación" ${ }^{14}$, como la epistémica "Arqueología" son irreconciliables como continuidad y transición. Ya vemos en este orden de ideas que ruptura y no-transición son las categorías fundamentales de lo his tórico.

Para Welsch, Herder se rebela antes que Hegel contra la presión de lo unificante y defiende la peculiaridad diacrónica de los mundos históricos. Kant defendió inclusive la discontinuidad sincrónica de los diferentes tipos de

\footnotetext{
${ }^{13}$ Jean François Lyotard. Le postmoderne expliqué... p. 143.

${ }^{14}$ Prefeniríamos traducir Schickung por Destino Manifiesto. Pero el sentido restringido que tiene el término, referido a la anexión en el siglo XIX, de territorios en el suroeste y noroeste y de las islas en el Pacífico y en el Caribe por parte de los Estados Unidos. nos inhibe de manera igualmente manifiesta.
} 
racionalidad; es por ello que habla del uso cognitivo, moral y estético de la razón. Este planteamiento kantiano nos hace entender el carácter heterogéneo de la razón; la coherencia o articulación de sus formas sería precaria y, según los posmodernos, falla siempre allí donde se busca deletrearla de manera compacta. Este finitismo fundamental de la razón, tanto en Herder como en Kant, que niega las totalizaciones, constituye uno de los pilares argumentativos de la posmodernidad. La posmodemidad tiene a su haber, además, un árbol genealógico de gran alcumia en donde fundamentar su desconfianza histórica hacia la totalidad: aparecen en su ramaje filós ofos de calibre como Kierkegaard y su inclinación hacia la paradoja, el perspectivismo de Nietzsche y el explícito ataque de Adorno, quien dice que el todo es lo no-verdadero. Es un hecho pues, que la despedida de la totalidad es obra de varias generaciones.

\section{Melancolía de la totalidad e intereses de la pluralidad}

Mientras se experimente la disolución de la totalidad como pérdida, estamos en la modernidad, y una larga tradición filosófica que parece afincarse des de Pascal, nos confima los síntomas precursores de esta despedida que, como veremos, se resiente también como duelo. Sólo cuando se conforma una positiva percepción de esa despedida, entramos en la pos-modernidad.

Para Lyotard, el romanticismo es el caso ejemplar en el que se aprecian estas diferenciaciones, en centenares de experiencias del fin de la totalidad y de la pérdida del sentido, todas en el modo del duelo y con la esperanza típicamente romántica de volver a voltear la página, es decir, de elaborar el duelo, pero con el alma y la inteligencia puestas en la totalidad o el absoluto. Según Lyotard, es a esta época neo-romántica a la que pertenecieron el dandismo, el nihilismo y el pesimismo finisecular de Viena.

Desde este horizonte se emiten los juicios; por ello, lo que en la mira modema se ve como pérdida de la totalidad con el consiguiente lamento del duelo, es para la posmodernidad al contrario, ganancia de una multiplicidad que es además digna de ser acogida. Hay dos autores que, según Lyotard, ejemplifican la concepción de lo diferente: Musil y Adorno.

Musil, de quien se cita siempre su obra paradigmática ${ }^{15}$, plantea la oposición de violencia y amor, univocidad y alegoría, como dualidades ineludibles con las cuales sólo se puede establecer un trato correcto. A este trato le serviría un "secretariado terrestre para la exactitud y el alma". La ironía de la fórmula denuncia que la auténtica es peranza yerra siempre la meta. La fómula apunta a la unidad, pero ¿cómo aparece ésta? Como incesto, fusión, mística o cualquier otro estado, pero siempre dentro del desgarramiento pleno. Así culmina lo que conduce a la posmodernidad, aunque una y otra vez de manera en extremo

\footnotetext{
${ }^{15}$ Roben Musil, Der Mann ohne Eigenschaften, Hamburgo 1952. 464. (El hombre.sin atributos).
} 
penosa, una y otra vez postergada y siempre desesperanzada. Es, sin duda, el escenario de lo que en alemán se llama Die Romantik.

De manera parecida ha constatado Adorno una polaridad, la misma de Musil, sólo que en Adorno va a llamarla construcción y mimesis, historia y naturaleza, y con más énfasis que Musil, puntualiza su imposible correlación. "El estado de reconciliación no anexaba lo extraño con filosófico imperialismo, sino que su suerte consistiría en que mantiene lo lejano y lo diferente en la garantía de lo cercano, allende de lo heterogéneo como de lo propio". Para Adorno el romántico se identifica por "dolor de mundo, sufrimiento y enajenación" ${ }^{16}$, (De manera parecida evalúa Lyotard la posición de Adorno: anticipa en mucho a la posmodernidad pero en el fondo permanece prisionero en el diagnóstico del derrumbamiento de la modernidad).

La posmodernidad, como contrastación con estos autores, no opera ni en el terreno, ni en el horizonte, ni con los medios de la reconciliación. Conoce la Unidad sólo como virtual, en cuanto abierta, y prefiere tener a la vista las constelaciones elementales de la pluralidad. Siguiendo el hilo de estas ideas, Welsch va a considerar el prefacio de las Investigaciones filosóficas de Wittgenstein como el prólogo de la posmodemidad.

\section{Legitimación histórica y filosófica}

Para los posmodernos, la legitimación no puede desligarse de la experiencia histórica y Lyotard encuentra en esta experiencia que el poder del dispositivo narrativo garantiza la legitimidad: “...cubre (el dis positivo) multiplicidad de familias de frases y de géneros de discursos posibles, envuelve todos los nombres... diacrónica y paracrónicamente asegura el dominio del tiempo y por ende el de la vida y la muerte"17. Hay pues una gramática en esta experiencia histórica cuyo código debe ser descifrado para poder ser esclarecida internamente con los supuestos insitos en su racionalidad propia. Creemos que con los tres ejemplos siguientes, Welsch ilus tra de manera sutil los s íntomas del síndrome posmoderno:

Ejemplo 1. La ciudad de Munich vivió al final de los años sesenta, a causa de los preparativos para los juegos olímpicos, un gigantesco impulso modemizador; por toda la ciudad se colocaron avisos tres veces más grandes que el tamaño estándar, en los que se leía: "MUNCHEN WIRD MODERN" (Munich se moderniza). Un buen día, un peatón abstraído en los pensamientos que agobian a todo citadino posmoderno, vuelve a leer el aviso, pero no sabe por qué lo entiende diferente: "MUNCHEN WIRD MODERN"; el desplazamiento de la acentuación prosódica hace que el adjetivo MODERN (moderno), se convierta en MODERN, lo que en español puede traducirse por podrirse o enmohecerse, asumiendo

\footnotetext{
${ }^{16}$ Theodor W. Adorno. Negative Dialektik, Frankfurt a. M. 1975. 192.

${ }^{17}$ J.F. Lyotard. Le postmoderne expliqué..., p. 52. 
entonces el distraído y cogitabundo peatón, que Munich se pudre. Un anuncio de modernización y progreso se ha convertido en la profecía de la putrefacción y la debacle de todo un mundo. Tal metamorfosis de lo utópico en una perspectiva catastrófica, pertenece según Welsh, a las experiencias iniciales de la posmodernidad.

Ejemplo 2. Estas experiencias no caen evidentemente del cielo, sino que emergen del infierno de la historia; es lo que sospecha Walter Benjamin en su Tesis para un concepto de la historia donde él habla del "ángel de la historia", una figura que representa el progreso. Pero tal como el Jano de los romanos, tiene una mirada para el futuro y otra para el pasado, pero en éste siempre ve él una única catástrofe, "que amontona bajo sus pies de manera reiterada, ruinas' sobre ruinas". Así es como se ve el progreso: el espanto de poder ser barridos por un huracán regresivo.

Ejemplo 3. La imagen decepcionante que tiene Musil de todo Orden lo patentiza de la siguiente manera: "Imagínate el Orden. O represéntate si quieres un gran pensamiento primero, luego uno más grande y después todavía uno más grande aún, y siempre otro más grande; y sobre esta muestra imagínate siempre un orden más grande y mejor en tu cabeza. Primero será algo tan simpático como el cuarto ordenado de una vieja solterona y tan aseado como aquél de un caballo mimado; luego majestuoso como una brigada que marcha en formación; después magnífico como cuando uno, saliendo del casino a la media noche, le grita a las estrellas 'Mundo entero, atención, fimes, con compás marchen!'. O digamos también que el orden es al comienzo como un recluta torpe a quien se le enseña a marchar como debe ser; después como cuando tú en tus sueños te escapas de una torre y vas directamente a la oficina del ministro de defensa; pero ahora, imagínate 'un orden totalmente civilizado, íntegro, universal, un orden total de la humanidad: así es como yo me imagino el frío de la muerte, su rictus mortis, un paisaje lunar, una epidemia de geometrías ${ }^{18}$. Conclusión: el sueño de la ilusión deviene en su totalización la pesadilla de la desilusión.

La posmodernidad está penetrada por el convencimiento de que la totalidad sólo surge por la absolutización de lo particular, y que por ello indefectiblemente está ligada a la opresión de otras particularidades. Es ésta la inteligencia (su Einsicht, el insight anglosajón) que ha extraído de la his toria y de su experiencia. De aquí que su vocación radical sea democrática. La democracia es una forma de organización no sólo para el consenso, sino mejor para el disenso de exigencias y derechos. Su base consensual -que naturalmente tiene y necesita, codificada en los derechos fundamentales-, se relaciona precisamente con ese derecho fundamental de la diferencia y la pluralidad y se afana en asegurar que a ese

\footnotetext{
${ }^{18}$ R. Musil, op. cit.
} 
derecho fundamental no se le atraviese en el camino algún mandato de contenido unificante de secuelas ilegales ${ }^{19}$

La posmodernidad toma en serio ese principio constitutivo de la democracia moderna. Más aún, es sólo ella la que en primer lugar aprovecha plenamente ese principio intrínseco de la democracia y es sólo ella la que en primer lugar pone en relieve el auténtico nervio de cualquier sentimiento democrático.

\section{Epílogo: ¿quiénes son los niños de Lyotard?}

Nunca entendimos, has ta haber concluido la lectura del libro de J. F. Lyotard, Le postmodeme expliqué aux enfants ${ }^{20}$, en su capítulo 10 titulado Adresse au sujet du cours philosophique (Envío a propósito del curso filosófico), quiénes podrían ser niños tan inteligentes, situados en algún lugar del primer mundo civilizado, tecnoindustrial, culto y archisofisticado, capaces de leer una obra que ha significado un esfuerzo sostenido y exige una cultura filosófica más allá de los cánones que regulan un curso de filosofía en la nomalidad tercemundista. Pero una lectura atenta nos revela a ese niño como el símbolo del status nascendi de ese hombre tratando de orientarse en el torbellino de solicitaciones divergentes, inevitables en toda época de crisis o transición. Lo que más nos importa es que, según Lyotard, ese niño es parte constitutiva y siempre actuante en el sujeto penetrado por el virus de la bulimia filosófica.

Para Lyotard, curso filosófico apunta a hilo en el tiem po, lo cual hace inteligible comprender el aprender y enseñar filosofía, el educar e instruir en general, en cuanto filosofía como acto y no como potencia. (Aquí denuncia Lyotard su fidelidad confesa a Aristóteles). Y sólo desde este concepto dinámico de una filosofía en acto, vamos a entender la apuesta mayor que, según Lyotard, se juega en la reflexión filosófica desde Protágoras -con su hombre, medida de todas las cosasy Platón con su porfía en la creación de un Estado regido por filósofos o tiranos reeducados.

Sólo en esta dinámica, las palabras Formación y Bildung se nos revelan en su signiticancia comprometedora ${ }^{21}$. ¿Qué es pues lo significante y comprometedor? Formación, Formung o Bildung tienen como supuesto que l'esprit des hommes ne leur est pas donné comme il faut, et doit étre ré-formé ${ }^{22}$. El subrayado nuestro apunta a esa necesidad de comprometemos en la búsqueda y conquista de ese

\footnotetext{
${ }^{19}$ Cf. Estanislao Zuleta. Sobre la Idealización en la Vida Personal y colectiva. Procultura, 1985. Bogotá.

${ }^{20}$ Es pertinente observar que en la edición francesa. aux enfants, "a los niños" no se halla entre paréntesis, como es el caso de la mediocre traducción española de la Editorial Gedisa, traducción que por múltiples aspectos, es un atentado desleal a la inteligencia del asunto. ¿Existirá tutela para tales casos?

${ }^{21}$ Es diciente al respecto la aposición en el título de la célebre obra de Werner Jaeger: Paideia, Die Formung des Griechischen Menschen (el subrayado es nuestro). Trad. esp. FCE México, 1983.

22 J.F Lyotard. Le postmoderne expliqué...p. 142 
Espíritu que no se nos ha dado comme / fáut, como debiera ser, y que además debe ser re-formado, lo cual lleva a concluir a Lyotard: el mons truo de los filósofos es la infancia, pero es también su cómplice. La infancia les dice que el Esprit (inteligencia intelectiva) no les ha sido dado, pero que sí es posible alcanzarlo.

Pero hay un agravante mayor en esta monstruosidad infantil para el filósofo: por sobreabundancia de Padres, no tiene ninguno. Es un huérfano de una especie rara. Esa orfandad lo remite a un consuelo pírrico pero a un reto mayor: filosofar es ante todo una autodidáctica. Los psicoanalistas tienen sólo un Padre, y un anális is fundante único: el auto-análisis de Freud y sus textos. A él y a ellos se remiten siempre y no hay posibilidad de autodidaxis, Es una familia unida alrededor de un padre único y venerado.

Como los filósofos no tenemos Padre, tenemos que empezar siempre de nuevo, volver a gatear para aprender a caminar. En el curso filosófico no se puede ser maître, maestro, puesto que no se puede maîtrisser, amaestrar, el curso de ese río. No se puede exponer un problema, echarse al agua, sin exponerse, es decir, nadar. Indagar un tema, el de la fomación por ejemplo, sin resultar siendo cuestionado, interrogado por el tema mismo, de la misma manera que no se podría enseñar el nado, haciendo énfasis en el vado o distrayendo al niño con discursos retóricos en la orilla del río (éste es el facilismo al que como tentación recurrente están expuestos los profesores de filosofía).

Re-comnzencer, quiere decir volver a gatear, para volver a caminar y aprender a nadar. Ese monstruo niño no es el padre del hombre, ni su maestro como diría Freud, sino que, según Lyotard, se halla justo en medio del hombre, en tanto que su de-curso y en cuanto su derivar posible y amenazante. Niño o autodidacta no quiere decir aquí que no se aprenda nada de los otros, sino que sólo se aprende en la medida en que los otros me enseñen a desaprender. Heidegger lo expresa de manera más poética: Lehren, enseñar, ist leeren lassen!, es permitir despojarse... vaciándos $\mathrm{e}^{23}$

Pero ¿cómo se des-aprende si quiero aprender? El texto filosófico me desaprende, esto es, me desconcierta en un ejercicio de persistente paciencia. (Paciencia me remite a paciente, adolorido y agobiado por una aflicción: éste es el dolor del desgarramiento del Espíritu que para Hegel, sale-de-sí, es la proeza y la prueba en la carrera de obstáculos comentada más arriba). Esa larga carrera de obstáculos, el largo camino del filosofar en Platón, el largo curso de la lectura filosófica en Lyotard, es todo ello uno y lo mismo, y nos dice además que no se acaba nunca de leer, que sólo podemos comenzar siempre de nuevo, qu 'on n 'a pas lu ce qu' on a lu, "que no se ha leído lo que se ha leído". Es por consiguiente un ejercicio de escucha ${ }^{24}$. El niño-filós ofo huérfano busca su familia auscultando

\footnotetext{
${ }^{23}$ M. Heidegger. ¿Qué significa pensar? Ed. Nova, Buenos Aires. 1978.

${ }^{24}$ Écoute, sustantivación de écouter, es el' escuchar francés.

Llega a los oídos galos como escolter en la lengua del medioevo, en sus siglos X a XII. Era lo que quedaba del bajo latín ascultare. auscultare. Es para nuestro español, la escucha sigilosa que 
en la escucha las voces de sus padres griegos y la de esa mujer vieja pero seductora que sus abuelos des de siempre llamaron Verdad.

Lyotard es pesimista frente a la democratización, léase masificación, de la enseñanza filosófica. ...Jeter duns le cours philosophique des esprits que $n$ ' $y$ enlrent pas, (Vide, p. 149, Op. cit.). Le parece inaceptable una didáctica de la seducción, "profes" convertidos en Alcibiades de baja alcurnia: el trabajo de anámnesis y la elaboración paciente en el acto del philosophieren kantiano no puede confundirse con el reclutamiento de clientes en las zonas de tolerancia, que es lo que en francés significa el racolage (Vide, p. 149). En un mundo donde se habla el idioma del intercambio económico, generalizado a todos los aspectos de la vida, abarcando hasta los afectos y los placeres, el idiolecto del curso filosófico no parece tener derecho de ciudadanía. No hay juez para dirimir el diferendo; entre estudiantes y profesores, inmersos en este escenario del time is money, los unos se convierten en víctimas de los otros. No hay cabida entre ellos, ni rara la dialéctica, ni para la dialógica. Sólo hay un espacio posible para la agonística.

Pero Lyotard nos consuela: “... hay quizás más infancia disponible para el pensar a los 35 años que a los 18. Y más aún, fuera de los cursos de estudios que adentro". El nuevo lema del pensamiento didáctico reza entonces: Buscar la infancia allí donde se encuentre, inclusive fuera de la infancia. Esa infancia a la búsqueda de la cual nos afanamos dentro de nosotros, fuera de nosotros, dentro y fuera de los cursos filosóficos, es la misma enfance retrouvée, en el tiempo perdido de Marcel Proust, la infancia que hace posible leer y re-leer para desaprender y des-concertarse agonísticamente con "La Posmodernidad explicada a los niños" (sin paréntes is, esta vez!) de Jean François Lyotard.

\section{BIBLIOGRAFIA}

ADORNO, Theodor W. Negative Dialektik. Frankfurt, a. M., 1975.

ALBERT, Hans. Traktat üb er Kritische Vernunft. Tübingen, 1980.

DE ONÍS, Federico. Antología de la Poesía Española e Hispanoamericana. Madrid, 1934.

GUTIÉRREZ GIRARDOT. Rafael. Mordernismo, supuestos históricos y culturales. Bogotá, FCE. 1987.

HABERMAS, Jürgen. El discurso filosófico de la Modernidad. Buenos Aires, Taurus, 1989.

HEIDEGGER, Martin. ¿Qué significa pensar? Buenos Aires, Editorial Nova, 1978. HIGGINS, Dick. A Dialectic of Centuries. Notes Towards a Theory of the New Arts.

New York, 1978.

ausculta en busca de signos no escritos en lo escrito y no dichos en lo dicho. Para Heidegger, es Hören, escuchar, que remite a Ge-hören, pertenecer. 
JAEGER. Werner. Paideia, Die Formung des Griechischen Menschen. Traducción española, Paideia. México, Fondo de Cultura Económica, 1983.

LAERMANN, K. Lacancan und Derridadá. Über die Frankolatrie in den Kulturwissenschafen, Kursbuch 84. 1986.

LYOTARD, Jean François. La condition postmoderne. Rapport sur le savoir. Paris, Les éditions de minuit, 1979.

LYOTARD, Jean François. La Posmodemidad (explicada a los niños). Barcelona, Editorial Gedisa, 1994.

LYOTARD, Jean François. Le postmodeme expliqué aux enfants. Paris, Editions Galilée, 1968.

MUSIL, Robert. Der Mann ohne Eigenschaften. Hamburgo, 1952.

PANNWITZ, Rudolf. Die Krisis der europäischen kultur Nürnberg, Werke, Bd. 2, 1917.

VILLANI, Antonio. Le chiavi del postmoderno: un dialogo a distanza. Revista il Mulino, 1986.

WELSCH, Wolfgang. Unsere postmoderne Moderne. Berlin, Akademie Verlag. Vierte Auflage, 1993.

ZULETA, Estanislao. Sobre la Idealización en la Vida Personal y Colectiva. Bogotá, Procultura, 1985. 